\title{
THE OUTCOME OF ACUTE OTITIS MEDIA (A REPORT TO THE MEDICAL RESEARCH COUNCIL)
}

BY

\author{
JOHN FRY, M.D., F.R.C.S., AND J. B. DILLANE, M.B., F.R.C.S. \\ General Practitioners, Beckenham, Kent \\ R. F. MCNAB JONES, F.R.c.s. \\ St. Bartholomew's Hospital, London \\ GRAHAM KALTON, M.Sc. (Econ.) \\ The London School of Economics \\ AND \\ EILEEN ANDREW, S.R.N.
}

Although acute otitis media is now a much less serious condition than it was in the pre-antibiotic period, it is still very frequent, probably affecting at least a quarter of all children in the United Kingdom (Fry, 1961; Lowe, Bamforth, and Pracy, 1963; Medical Research Council, 1957; Miller, Court, Walton, and Knox, 1960; Neil, Harrison, Morbey, Robinson, Tate, and Tate, 1966).

The final outcome has been in some doubt. Nowadays serious complications are rare and mastoidectomy is seldom necessary, but hearing does not always return to normal.

Thus, in the Medical Research Council Report (1957), 6.5\% were 'deaf' (as tested by crude methods) at the end of 6 months; Neil and his colleagues (1966) noted that $20 \%$ had a hearing loss of more than 20 decibels in one or more frequencies after 6 months and in $6.5 \%$ this deafness was present still after 3-4 years; Lowe et al. (1963) reported that in $25 \%$ of their children there was a 'significant deafness' of 30 decibels or more 6 months after the attack; Olmsted, Alvarez, Moroney and Eversden (1964) reported deafness (15 decibel loss) in $12 \%$ of a group of children in Philadelphia 6 months after an attack of acute otitis media; and Reed, Struve, and Maynard (1967), in a cohort study of Eskimo children, reported deafness (loss of 25 decibels or more) in $31 \%$ after $3-4$ years.

Although the criteria of 'deafness' are not directly comparable, it is evident that in all studies there is an appreciable proportion of children with some hearing defects after attacks of acute otitis media.
It is well known that deafness can impede the educational progress of children (Ling, 1956).

Faced with these differences in published reports we considered it important to determine the state of hearing in children (many now young adults) some years after suffering attacks of acute otitis media, and to try to correlate this with possible causal factors.

\section{MATERIAL AND Methods}

The material comprised the $\mathbf{4 0 3}$ persons diagnosed as suffering from acute otitis media between 1957 and 1962 in a south-east London middle-class general practice and followed up and assessed in 1966-67. The social class distribution was social class I, $1 \%$; II, $12 \%$; III, $54 \%$; IV, $31 \%$; and V, $2 \%$.

Controls were a sample of the same age and sex who had no previous history or record of acute otitis media. They were selected from the practice age-sex register and were seen, tested, and assessed in the same manner as the cases. It was considered that a one-in-five matched control sample was a reasonable number and 122 controls were selected.

Retrieval of records was easy since a system of punched cards has been in use during the whole period. All those who had suffered from acute otitis media during 1957-62 and were still in the practice at the beginning of 1966 were invited to attend for a hearing test.

Acute otitis media was defined as 'an acute condition with earache and a red drum, or, with sudden ear discharge and a perforation, either 
following earache or arising de novo in a person with no previous history of chronic ear disease'. Treatment was the responsibility of the general practitioner in charge of the case. Antibiotics were not used routinely.

At the first screening, records were completed on attacks of otitis media, associated diseases, and family history, and audiograms were carried out (by E.A.) using an Amplivox 51 audiometer in a quiet room under standard conditions.

Those with a hearing loss of 20 decibels or more in one or more frequencies were referred for retesting and clinical assessment by an otologist (R.F. McN.J.). One hundred and eleven out of 403 (28\%) with a history of acute otitis media were referred and 17 out of $109(16 \%)$ of controls.

'Deafness' was considered to be present when repeat audiograms showed a hearing loss of more than 20 decibels in two or more frequencies.

The reason why we adopted less severe criteria of hearing loss at the first screening, i.e., a loss of 20 decibels in at least one frequency, was that we did not want to miss any 'deaf' persons. We were prepared to send more subjects for re-testing than we expected to be found to be deaf. We were willing to have 'false positives' on screening but not 'false negatives'.

A number of those who were 'deaf' were admitted to hospital for further investigation and treatment.

\section{RESULTS}

There were records of 502 persons who had suffered from acute otitis media during 1957-62. Of these, 68 had moved out of the practice by 1966 and another 31 did not attend when invited, so that the overall response was $\mathbf{8 0} \%$. However, this represents a $93 \%$ response of those in the practice at the time of the study. Of the 122 controls, 13 did not attend (a response rate of $90 \%$ ) (Table $\mathrm{I}$ ).

TABLE I AGES AT FOLLOW-UP

\begin{tabular}{l|c|c|c|c}
\hline \multirow{2}{*}{ Age (yrs) } & \multicolumn{2}{|c|}{ Acute Otitis Media } & \multicolumn{2}{|c}{ Controls } \\
\cline { 2 - 5 } \cline { 4 - 5 } & $\begin{array}{c}\text { Males } \\
\%\end{array}$ & $\begin{array}{c}\text { Females } \\
\%\end{array}$ & $\begin{array}{c}\text { Males } \\
\%\end{array}$ & $\begin{array}{c}\text { Females } \\
\%\end{array}$ \\
\hline $5-7$ & 7 & 7 & 4 & 5 \\
$8-9$ & 13 & 8 & 14 & 12 \\
$10-14$ & 43 & 52 & 45 & 50 \\
$15+$ & 37 & 32 & 37 & 33 \\
\hline & 100 & 100 & 100 & 100 \\
\hline & $(214)$ & $(189)$ & $(51)$ & $(58)$ \\
\hline
\end{tabular}

- Numbers of persons in parentheses

Particular note was made of the period since the last attack and it was found that $18(4 \%)$ were seen within a year of the last attack, $173(43 \%)$ up to 5 years from the last attack, and $212(53 \%)$ more than 5 years from the last attack.

The index (first) attacks of acute otitis media in this series showed the typical pattern of the condition in a middle-class area with peak incidence in the pre-school and early school years (children begin to attend school at age 5 in this area).

The 403 persons suffered a total of 1,446 attacks of acute otitis media (a mean of 3.6 attacks per person). Discharge occurred in $20 \%$ of attacks. Antibiotics were prescribed in $54 \%$ (219) of persons and in $20 \%$ of attacks.

At the final assessment it was found that, on our definition of hearing loss of 20 decibels in two or more frequencies, 68 were 'deaf'. This represents a rate of $17 \%$ (68 out of 403 ) of all those who had suffered from acute otitis media. Only 5 out of 109 controls, a rate of $4.5 \%$, met our criteria of 'deafness'. The difference is highly significant $\left(\chi^{2}=10 \cdot 59\right.$, 1 d.f.; $P<0.01$ ).

\section{Factors Associated with Deafness}

We were concerned to discover any factors that could be related to the development of deafness in our patients with acute otitis media and we analysed our material to provide comparisons between nondeaf and deaf groups in those with a past history of acute otitis media and in our controls.

SEX DIFFERENCES Significantly more females than? males were found to be deaf- $12 \%$ of 214 males compared with $21 \%$ of 189 females $\left(\chi^{2}=5.89\right.$; 1 d.f.; $\mathrm{P}<0.05$ ). Among the five controls found to be deaf there were three males and two females.

Siblings We were interested in the possibility of increased liability to cross infections in large families and in children with older siblings.

Whereas $26 \%$ (88) of the non-deaf group were only-children, the proportion was $10 \%(7)$ in the deaf group $\left(\chi^{2}=8.01 ; 1\right.$ d.f.; $\left.P<0.01\right)$.

It was not possible to separate the 'sibling' factor from that of social class, because there were so few children in social classes I and V (3\%). In fact, it was a middle class area.

Age and Time since Last Attack A difference was noted between the deaf and non-deaf groups in the length of time since the last attack of acute otitis media and in the ages at examination. A higher proportion of the deaf group $(41 \%)$ were assessed within three years of the last attack than in the nondeaf group $(21 \%)\left(\chi^{2}=12.3 ; 1\right.$ d.f.; $\left.P<0.01\right)$.

It may well be that, with time, deafness may have resolved naturally and so, in calculating possible associated factors, we excluded those with a history of an attack of acute otitis media within three years. 
When this was done it was found that $13 \%$ of those patients with acute otitis media who had experienced their last attack more than three years from assessment were deaf (compared with $17 \%$ for all acute otitis media patients). This rate of $13 \%$ is still significantly different from the rate of $4.5 \%$ deafness in controls ( $\chi^{2}=6.07 ; 1$ d.f.; $\left.P<0.05\right)$.

The age at which the first (index) attack occurred was not different in the non-deaf and deaf groups. In the non-deaf group, $22 \%$ (77) had their first attack in their first three years of life, $56 \%$ (188) between 3 and 7 years and $21 \%(70)$ after 7 ; in the deaf group, the figures were $22 \%$ (15) for those whose first attacks occurred in the first three years; $51 \%(35)$ between 3 and 7 years, and $27 \%$ (18) for attacks after the age of 7. (Exclusion of those with an attack within the past three years did not alter the rates.)

It had always been our clinical impression that those whose attacks began in infancy were more likely to suffer deafness, but this has not been supported by our studies, since the age of onset did not affect the outcome.

The age at the last attack was similar also in the two groups-the proportions with their last attack over the age of 7 were $62 \%$ of the 335 in the non-deaf group and $54 \%$ of the 68 in the deaf group $\left(\chi^{2}=\right.$ $1 \cdot 18 ; 1$ d.f.; N.S.). Exclusion of those with an attack in the past three years made no difference.

NUMBER of ATTACKs There were no differences in the mean number of attacks in the non-deaf and deaf groups.

The non-deaf group averaged 3.6 attacks each and the deaf group 3.8 attacks per person. Put in another way, $38 \%$ of the 335 non-deaf had a single attack and $31 \%$ of the 68 who were deaf $\left(\chi^{2}=1 \cdot 20 ; 1\right.$ d.f.; N.S.) and the proportions of those having six or more attacks were $17 \%$ and $20 \%$ respectively.

Discharge There were differences in the proportions with a history of discharge in one or more attacks. In the non-deaf group, discharge occurred in $26 \%$ of attacks and in the deaf group in $34 \%$.

ANTIBIOTICs Antibiotics were used more frequently in the deaf group (for $63 \%$ (43) of persons or in $25 \%$ of all attacks) than in the non-deaf group (49\% (164) and $18 \%$ of attacks). The difference is significant $\left(\chi^{2}=4.61 ; 1\right.$ d.f.; $\left.P<0.05\right)$.

Removal of Tonsils AND AdenoIds The proportion in whom tonsils and/or adenoids had been removed were $15 \%(51)$ in the non-deaf group and $22 \%(15)$ in the deaf group $\left(\chi^{2}=1.93 ; 1\right.$ d.f.; N.S.). The rate was $12 \%$ in the controls.
The rate for adenoidectomy only was $5 \%(18)$ in the non-deaf and $10 \%$ (7) in the deaf groups $\left(\chi^{2}=\right.$ 2.35; 1 d.f. N.S.).

Associated Allergies Eczema, wheezy chests or nasal allergies were prevalent equally in the non-deaf and deaf groups of acute otitis media cases and in the controls (Table II).

TABLE II

PREVALENCE OF ASSOCIATED ALLERGIES IN ACUTE OTITIS MEDIA (DEAF AND NON-DEAF GROUPS) AND CONTROLS

\begin{tabular}{l|c|c|c}
\hline & \multicolumn{2}{|c|}{ Acute Otitis Media } & Controls \\
\cline { 2 - 3 } Persons with History of: & $\begin{array}{c}\text { Non-deaf } \\
\%\end{array}$ & $\begin{array}{c}\text { Deaf } \\
\%\end{array}$ & $\%$ \\
\hline Eczema & 12 & 13 & 10 \\
Wheezy chest & 22 & 23 & 24 \\
Nasal allergy & 35 & 35 & 40 \\
\hline No. of persons & $(335)$ & $(68)$ & (109)
\end{tabular}

FAMILY History There was a correlation between a liability to deafness and a positive family history of ear disease. A progressive rise in frequency was noted from controls, through non-deaf to deaf groups $\left(\chi^{2}\right.$ for trend $=6.50 ; 1$ d.f.; $P<0.05$ ) (Table III). For family history of deafness the trend was in the same direction but was not significant ( $\chi^{2}$ for trend $=1.72 ; 1$ d.f.; N.S.). No association was noted with an allergic history.

It seems therefore that there may be a familial predisposition to acute otitis media and deafness.

TABLE III

FAMILY HISTORIES AND ACUTE OTITIS MEDIA (DEAF AND NON-DEAF GROUPS) AND CONTROLS

\begin{tabular}{l|c|c|c}
\hline \multicolumn{1}{c|}{$\begin{array}{c}\text { Persons with } \\
\text { Family History of: }\end{array}$} & \multicolumn{2}{|c|}{ Acute Otitis Media } & Controls \\
\cline { 2 - 3 } & $\begin{array}{c}\text { Non-deaf } \\
\%\end{array}$ & $\begin{array}{c}\text { Deaf } \\
\%\end{array}$ & $\%$ \\
\hline Ear disease & 11 & 18 & 5 \\
Deafness & 19 & 25 & 16 \\
Allergy & 36 & 43 & 42 \\
\hline No. of persons & $(335)$ & $(68)$ & (109) \\
\hline
\end{tabular}

Abnormalities In Deaf Group a perforation was found in one ear, 15 had scarred drums, tubal dysfunction, i.e., retraction of drum or suspected fluid (secretory otitis), was noted in 25 ears, and a perception loss was noted in one person.

A follow-up is being carried out on these persons to determine whether further surgical treatment improves their hearing.

\section{Discussion}

Our finding that $17 \%$ of persons, mostly children, were 'deaf' at the end of a follow-up extending 5-10 
years from their first attack of acute otitis media merits careful consideration and possible action.

A long follow-up is necessary in a condition that is liable to recurrences and spontaneous changes in the state of hearing. However, even when those with a history of an attack of acute otitis media within three years of an assessment were excluded, the proportion of those who were deaf was $13 \%$. Our period of follow-up has been longer than in any previously recorded studies but, even so, it may not be long enough for a final assessment.

We used an arbitrary definition of deafness, a hearing loss of 20 decibels or more on two or more frequencies ( 125 to 4000 c.p.s.) as recorded on a pure tone audiometer. We were forced to this arbitrary definition because there is no recognized international standard and we suggest that the World Health Organization might perhaps consider formulating some agreed standards of measurement in this type of screening.

Whatever the disagreement with our standard of measuring deafness, we consider that a hearing loss of 20 decibels or more in at least two frequencies does lead to serious social and educational handicaps and difficulties in school-children; so the fact that $17 \%$ in our group were below this standard has serious implications.

We attempted to define factors that might be associated with the development of deafness which could be used to pick out children who might be particularly vulnerable and who would be investigated specially. We found no useful and practical factors. Whilst there were correlations between deafness and a history of discharge, and a family history of ear disease, these are not selective enough to be of practical value.

We therefore recommend that all children, and in particular school-children who suffer from acute otitis media, should be considered as 'at risk' and require special investigation, assessment, and followup.

We recommend that in principle all children who have suffered an attack of acute otitis media and who are able to co-operate should have a hearing test six months or so following their attack. This test should be with an audiometer and carried out by a trained person. We found that one of us (E.A.) with general nursing experience could be trained quickly and become proficient at testing hearing in the context of the working conditions in general practice and that her results were corroborated by those working in a hospital unit.

Those children with a hearing loss below a level to be defined and agreed upon should be seen, assessed, and followed up by a specialist in co- operation with the family doctor and the school medical service.

Ideally, the whole scheme should perhaps be based on general practice, and in large groups or health centres there should be one member of the team who would carry out such hearing tests. As noted, we found that a nurse can be trained for such work.

At present, because there are few large groups or health centres, and because we consider it is urgent that some scheme be introduced, we suggest that it may, as a temporary measure, be based on the school health service. The procedure might be for the family doctor to notify to the local school medical officer all cases of acute otitis media and to inform the parents that this is being done and that a follow-up is necessary. It will then be the responsibility of the school medical officer to arrange for the audiometric hearing test to be done six months after the attack. The results of the test will be sent to the family doctor who will presumably refer to a specialist those who are deaf.

We do not consider that such a scheme is beyond the present capacity or the resources of general practice, the school medical service or the hospital service.

\section{SUMmary}

A subjective hearing assessment, including audiometric records and examination by a specialist, was carried out on 403 children ( $93 \%$ response rate) who had suffered from acute otitis media 5-10 years previously. Seventeen per cent were found to have a hearing loss of 20 decibels or more in at least two frequencies compared with $4.5 \%$ of matched controls.

Deafness was more likely to occur in females than in males; in those children with siblings than in only-children; in those who had suffered discharge during any attack and in those with a family history of ear disease.

There was no correlation between deafness and age at which the first attack occurred, age at the last attack, total number of attacks of acute otitis media, or a history of associated allergies. No social class comparisons could be made as most children were in social classes II, III and IV.

The high incidence of deafness following acute otitis media in children indicates that some action is necessary to define and help these children who are 'at risk' both socially and educationally.

We recommend that a scheme be developed to pick out, assess, and manage these children. Hearing should be tested audiometrically 6-12 months after an attack of otitis media in all children who can 
co-operate in the test. Those with deafness should be referred to a specialist for assessment and follow-up.

This scheme could be based on general practice with close co-operation with the School Health Service and local hospital specialists.

This study was supported by a grant from the Medical Research Council to J.F.

\section{REFERENCES}

FrY, J. (1961). The Catarrhal Child. Butterworths, London.

LING, D. (1956). Annual Report of School Medical Officer for Reading for 1956.
Lowe, J. F., Bamforth, J. S., and Pracy, R. (1963). Acute otitis media: One year in a general practice. Lancet, 2, 1129.

Medical Research Council (1957). Acute otitis media in general practice. Ibid., $2,510$.

Miller, F. J. W., Court, S. D. M., Walton, W. S., and KNOX, E. G. (1960). Growing Up in Newcastle upon Tyne. Oxford University Press, London.

NeIL, J. F., Harrison, S. H., Morbey, R. D., Robinson, G. A., TATE, G. M. T., and TATE, H. T. (1966). Deafness in acute otitis media. Brit. med. J., 1, 75.

Olmsted, R. W., Alvarez, M. C., Moroney, J. D., and EVERSDEN, M. (1964). The pattern of hearing following acute otitis media. J. Pediat., 65, 252.

ReEd, D., Struve, S., and Maynard, J. E. (1967). Otitis media and hearing deficiency among Eskimo children: a cohort study. Amer. J. publ. Hlth, 57, 1657. 